\title{
Programmed stimulus input and the development of a perceptual set in schizophrenic and normal subjects'
}

\author{
Robert L. Weiss and Emilia I. Nordtvedt \\ PALO ALTO VA HOSPITAL AND STANFORD UNIVERSITY
}

\begin{abstract}
Abstraet
The development of a central perceptual set was studied in 50 schizophrenic patients and 18 normals. Either a temporally uniform or a temporally random sequence of set inducing trials was given. Following these, the perceptual content was switched without prior warning. A decrement in perceptual efficiency at the point of the switch was taken as an indication of a facilitating set for one kind of content over another. Both the patient and normal groups showed significant decrements, indicating that schizophrenic patients do form central sets. Only the normal group was prevented from developing a set by the random sequence of trials.
\end{abstract}

\section{Problem}

The theoretical controversy over central $v s$. peripheral locus of set (Mowrer et al., 1940; Mowrer, 1941; Freeman, 1940) has been updated in two experiments by Cavanaugh (1958). Her experiments reflect the centralist positions of Hebb (1949), and of Bugelski (1956); especially the latter's rapprochement between "cell assemblies" and rg's. Cavanaugh provided support for these positions with her (a) replication, with positive findings, of Mowrer's earlier set study, and (b) multiconditioned study of a task induced perceptual set involving otherwise overlearned content (letters and numbers). Given sufficient "training" on one type of stimulus, significant decrements in task efficiency were obtained when Ss were changed to another stimulus in the same modality.

The present study was concerned with two questions: (a) Do patients diagnosed as schizophrenic show evidence for a central task-induced perceptual set; and (b) can the development of such a set be altered by programming variability in set inducing trials? On reaction time tasks schizophrenic subjects show a characteristic inability to maintain a motor set (cf. Shakow, 1962; Zahn et al., 1961). Is there also impairment in the development of central perceptual sets? Cavanaugh's (1958) and Shakow's (1962) work suggest the importance of temporal uniformity of trials but the role of temporal uniformity in developing a central perceptual set has not been answered by these studies.

\section{Method}

Two sets of slides were prepared, using a basic grid pattern, partially occupied by (a) the first nine consonants (letters), or (b) numerals $1-9$ (numbers). Placement in the cells was randomized. Letter slides were shown for $32-$ set inducing trials, followed by 32 number slides. The switch in content was without prior instruction, and all exposures were at .1 sec. A decrement in perceptual efficiency, from last letter slide to first number slide was taken as an indication of a set for letters. The information contained in either type of slide was comparable with such highly overlearned content, viz., letters and numbers.

Fifty hospitalized patients, diagnosed as schizophrenic, and 18 nonpatients were tested under either a Uniform or Random program of slide presentation. (Uniform-a fixed 10-sec. interval between successive slide exposures. Random-the time interval varied for each slide, with a mean time of $10 \mathrm{sec}$.) In both conditions, prior to each exposure, Ss were alerted to fixate the center of the viewing screen by a buzzer sound. Each $S$ recorded his perceptions on a paper replica of the screen grid. A symbol was scored as correct if also located in its appropriate cell.

\section{Results and Diseussion}

Under the two programs of slide presentation, Uniform and Random, patients significantly improved their tachistoscopic recognition of letters, $(\mathrm{F}=8.42 ; \mathrm{P}<.01$, for trials 1-32). The programs did not differentially

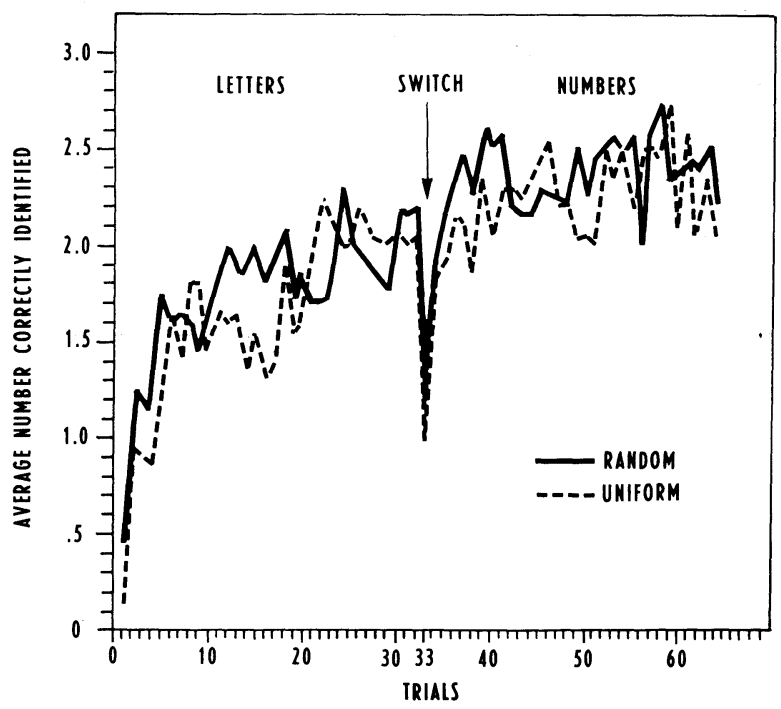

Fig. 1. Mean number of symbols (letters or numbers) correctly identified by patients on set-inducing and post-switch trials. Trial 33 performance represents point at which slide content changed. 
influence rate of improvement ( $F=1.14 ; 31 / 1488 \mathrm{df}$ ). Similar results were obtained for the post-switch trials $(33-64)$. The curves for mean number of correct symbols are presented in Fig. 1 for the patients in each program. The large decrements noted at the point of switch (between trials 32-33) were highly significant for each condition; $\mathrm{t}=4.75(\mathrm{P}<.001)$ and $2.58(\mathrm{P}<.02)$ for the Uniform and Random programs respectively. (None of the other adjacent drops were significant during these pre-switch trials.) The difference between the decrements was not statistically significant. The set inducing trials were clearly effective in facilitating perception of letter slides, although the programming procedures did not differentially influence the development of this central set in the patients.

For the nonpatients the programming variables contributed a significant source of variance (Trials $\mathrm{x}$ Program interaction, $\mathrm{F}=2.99 ; \mathrm{P}<.01)$. Inspection of the trial means indicated that the Random program produced considerable trial to trial variation, even though the Trials effect was significant $(\mathrm{F}=1.55$; $31 / 496 \mathrm{df} ; \mathrm{P}<.05$ ). Further, the decrement (at point of switch) in the Random program was not significant between trials $32-33$, but it was significant in the Uniform condition ( $t=1.95 ; \mathrm{p}<.05$, one-tail).

The patients showed a significant decrease in symbol recognition when the content changed without warning from letters to numbers. The decrement is all the more striking when we consider the relatively low level of symbol recognition attained by the patients in the 64 trials. Like Cavanaugh's (1958) normals, those in the present study averaged 3.6 symbols (or greater) by the end of the series.

The present findings replicate and extend the generality of Cavanaugh's (1958) evidence for the central locus of a perceptual set. Schizophrenic patients clearly develop a facilitating perceptual set, as do normals, but unlike normals, they appear to be unaffected by an attempt to program interference with the development of the set. The present findings raise the interesting possibility that nonpatients are influenced by variable intervals between trials, but that schizophrenic patients form a perceptual set even when conditions make this difficult on other grounds.

\section{References}

BUGELSKI, B. R. The psychology of learning. New York: Henry Holt Co., 1956.

CAVANAUGH, MAXINE C. A study of central facilitation or set with reference to closely similar stimuli, experience, and instructions. Unpublished doctoral dissertation, Univer. of Buffalo, 1958.

FREEMAN, G. L. "Central" vs. "peripheral', locus of set: a critique of the Mowrer, Rayman, and Bliss demonstration. J.exp. Psychol., 1940, 26, 622-628.

HEBB, D. O. The organization of behavior. New York: Wiley, 1949.

MOWRER, O. H., RAYMAN, N. N., \& BLISS, E. L. Preparatory set (expectancy) - an experimental demonstration of its central locus. J.exp. Psychol., 1940, $26,357-372$.

MOWRER, O. H. Preparatory set (expectancy)-furhter evidence of its "central", locus. J. exp. Psychol.; 1941, 28,166-133.

SHAKOW, D. Segmental set. Arch.gen. Psychiat., 1962, $6,1-17$.

ZAHN, T. P., ROSENTHAL, D., \& SHAKOW, D. Reaction time in schizophrenic and normal subjects in relation to the sequence of regular preparatory intervals. J. abn. soc. Psychol., 1961, 63, 161-168.

\section{Note}

1. This study was based on part of a master's thesis by the junior author under the direction of the senior author. 